\title{
Mehr Mut
}

\section{Liebe Leserin, lieber Leser,}

warum immer so kurz springen? Da wird ihr mal der Beifall der Automobilindustrie sicher sein: Die Deutsche Umwelthilfe (DUH) kritisiert zu Recht die abgeschwächten Vorgaben für sogenannte Komfortkamine in Stuttgart. Eine Entscheidung, die auch auf das Bundesgebiet ausstrahlt. Denn die Verordnung gilt nur für Öfen, die vor Januar 2015 errichtet wurden. Sie wirkt nur an Tagen mit Feinstaubalarm und nimmt bestimmte Feuerungsanlagen aus. Und sie gilt erst ab März 2017, also nach der diesjährigen Heizperiode. So hätte es Klaus-Peter Gussfeld vom BUND gegenüber dem Deutschlandradio lieber gesehen, „wenn dieses Verbot generell im gesamten Winterhalbjahr gegolten hätte“. Eine an sich erfreuliche Sache, Komfortkamine genauer unter die Lupe zu nehmen, wird somit konterkariert.

Stuttgart ist durch die Kessellage besonders hart von Smoggefahr bei Inversionswetterlagen betroffen. Die etwa 20.000 holzbefeuerten Kamine und Öfen in den Privathaushalten tragen mit $22 \%$ erheblich zur PM10-Feinstaubbelastung bei und sind damit zweitgrößter Verursacher. Der Straßenverkehr an Nummer 1 macht 50 \% aus, den Pkw-Fahrern und Pendlern drohen daher Verkehrsbeschränkungen und Fahrverbote ab 2018. Mit 63 Überschreitungstagen 2016 liegt die Feinstaubbelastung in der Großstadt immer noch deutlich über den erlaubten 35 Überschreitungstagen.

Gleichzeitig werden Maßnahmen, Emissionen zu senken und $\mathrm{CO}_{2}$-Ziele einzuhalten, auf Bundesebene unterlaufen, indem das Bundeskabinett ab 2019 den Steuervorteil für Autogas (LPG) streichen will. Die Bundesregierung enttäusche mit ihrem Beschluss das Vertrauen von 480.000 Autogas-Nutzern in Deutschland kommentierte Rainer Scharr, Vorsitzender des Deutschen Verbandes Flüssiggas (DVFG), den Entscheid sogleich. Dabei hätte man auch hier mehr tun können, um die ehrgeizigen politischen Ziele zur Luftreinhaltung und Treibhausgasreduktion zu erreichen. Denn der DVFG hatte vorgerechnet, dass im Vergleich zu fossilen Ottokraftstoffen (Benzin) der Alternativkraftstoff Flüssiggas $21 \% \mathrm{CO}_{2}$ pro Energieeinheit einspare. Flüssiggas sei eine Energie, die extrem wenig Feinstaub der PM2,5-Klasse emittiere und auch bei PM10-Emissionen „deutlich überlegen" sei.

Der große Sprung ist also gefragt, um unsere Gesellschaft voranzubringen. Die Politiker sollten sich bei Gesetzgebung und innovativen Projekten die Worte des neuen Bundespräsidenten Frank-Walter Steinmeier zu Herzen nehmen: „Lasst uns mutig sein“.

Herzliche Grüße, Ihr

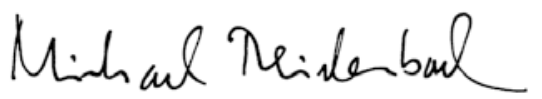

Dipl.-Ing. Michael Reichenbach Stellvertretender Chefredakteur

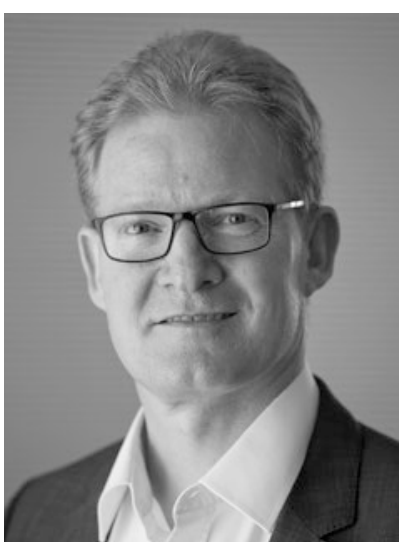

Wir

\section{entwickeln, was bewegt.}

\section{IAV - Ihr Partner \\ für Automotive Engineering}

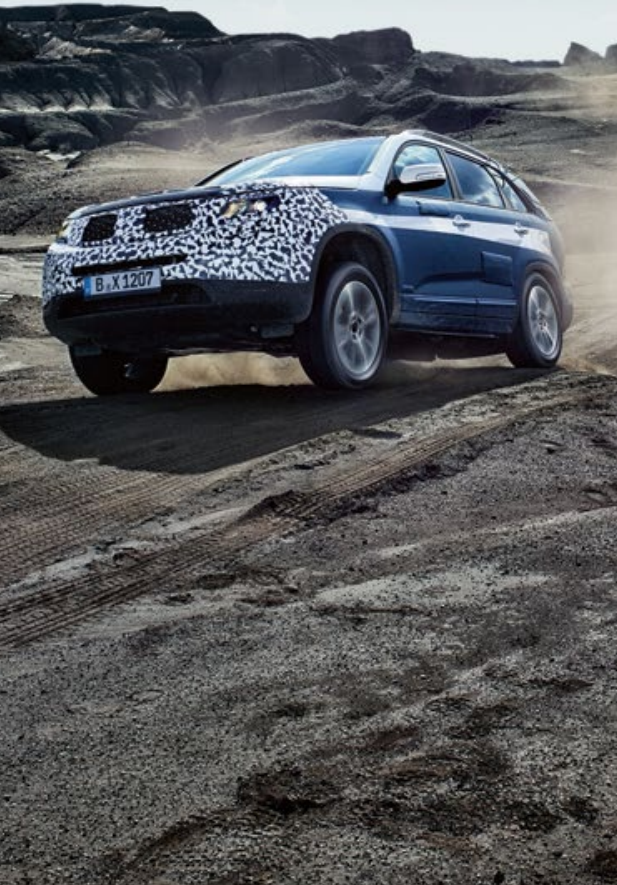

